\title{
INCIDENCE OF VARIOUS BENIGN MASS LESIONS OF THE NOSE IN 2015: A RETROSPECTIVE STUDY
}

\author{
B. Sudha' , P. S. R. Rajeswari², A. V. Ramana 3 , S. Surya Prakasa Rao ${ }^{4}$ \\ ${ }^{1}$ Assistant Professor, Department of E.N.T, Andhra Medical College, Visakhapatnam. \\ ${ }^{2}$ Assistant Professor, Department of E.N.T, Andhra Medical College, Visakhapatnam. \\ ${ }^{3}$ Assistant Professor, Department of E.N.T, Andhra Medical College, Visakhapatnam. \\ 4Professor, Department of E.N.T, Andhra Medical College, Visakhapatnam.
}

\section{ABSTRACT}

\section{AIM OF THE STUDY}

To know the incidence of different benign mass lesions of the nose and paranasal sinuses.

\section{MATERIALS AND METHODS}

The study was conducted in Government ENT Hospital, Andhra Medical College, Visakhapatnam, a Tertiary referral hospital in Andhra Pradesh which receives about 250 patients per day. The total number of patients examined in the year 2015 from January to December was 88,295. Among them 34,826 (39.44\%) patients attended with nasal symptoms like nasal obstruction, epistaxis, recurrent attacks of epistaxis, nasal discharge (Mucoid to mucopurulent), headache, post nasal drip and loss of smell; 111 ( $0.31 \%$ in the study group with nasal symptoms) patients had benign mass lesions of the nose.

\section{CONCLUSION}

In this series, the Nasal polyposis has evolved as the commonest cause of nasal obstruction among mass lesions of nose. Later was Nasopharyngeal angiofibroma and Inverted Papilloma, rarely Rhinosporidiosis and Fibrous dysplasia.

\section{KEYWORDS}

Mass Lesions of Nose, Nasal Polyps, Nasopharyngeal Angiofibroma, Inverted Papilloma, Rhinosporidiosis.

HOW TO CITE THIS ARTICLE: Sudha B, Rajeswari PSR, Ramana AV, et al. Incidence of various benign mass lesions of the nose in 2015: a retrospective study. J. Evolution Med. Dent. Sci. 2016;5(62):4392-4394, DOI: 10.14260/jemds/2016/1002

\section{INTRODUCTION}

The mass lesions of nose is the second commonest cause of nasal obstruction, the first being the deviated nasal septum with allergy. Out of all mass lesions, polypoidal masses in the nose is very common lesions encountered in clinical practice. ${ }^{1}$ It may be due to the most frequently occurring simple Nasal polyposis due to allergy or polypoidal lesions due to a variety of other pathologic entity ranging from infective granulomatous diseases to polypoidal neoplasms. ${ }^{2}$ High incidence of Nasal polyposis can be attributed to abundance of allergic patients owing to increasing pollution, non-availability of drugs for cure of allergy and lack of compliance to use prolonged medication. The recurrence rate is very high in nasal polyposis. This may be due to irregular follow-up and cessation of medical advice to use continuous usage of oral anti-histaminics and steroid nasal sprays. ${ }^{3}$ Avoidance of allergic food, dust and fragrant fumes has to be educated to the patients as the allergy is the predominant cause for the Nasal polyposis. The other benign mass lesions like Nasopharyngeal angiofibroma is common in adolescent males. Inverted papilloma is the next common, while Rhinosporidiosis and Fibrous dysplasia are rarely seen. This hospital being in Andhra Pradesh, which is adjacent to Orissa, we get referred cases of Rhinosporidiosis which are common in Orissa.

Financial or Other, Competing Interest: None.

Submission 26-04-2016, Peer Review 20-07-2016,

Acceptance 26-07-2016, Published 04-08-2016.

Corresponding Author:

Dr. S. Surya Prakasa Rao,

\#50-27-15/1

Seethammadhara NE

Visakhapatnam-530013.

E-mail:drssprao@gmail.com

DOI: $10.14260 /$ jemds/2016/1002

\section{MATERIALS AND METHODS}

This retrospective study was conducted in Government E.N.T Hospital, Andhra Medical College, which is tertiary referral hospital in Visakhapatnam in 2015 from January to December. The study compares sex differences and relative incidence of various benign mass lesions of the nose and paranasal sinuses. They occurred commonly in the sample consisting of patients in the age group 2 yrs. - 72 yrs., more in third and fourth decades with predominance in males.

The number of outpatients that attended Govt. E.N.T. Hospital during the study period was 88,295 . Out of the above, the number of patients that attended with nasal symptoms were 34,826 (39.44\%).

The number of patients presented with mass lesions of nose were 111 in the year 2015; $(0.31 \%$ in the study group with nasal symptoms).

All the above patients were first thoroughly examined in Outpatient Department by Anterior Rhinoscopy with Bull's eye lamp. Later they underwent diagnostic nasal endoscopy to come to provisional diagnosis. Routine blood investigations including Absolute eosinophilic count, X-ray and CT scan of Paranasal Sinuses were performed. The suspected lesions were taken for biopsy and sent for Histopathological examination to know the nature of mass.

\section{Inclusion Criteria}

1. Mass lesions arising due to Allergic, Fungal, Non-Specific and Specific infective pathology.

2. Benign tumours of nose and paranasal sinuses.

\section{Exclusion Criteria}

1. Malignant lesions of the nose.

2. Mass lesions of intracranial origin.

3. Mass lesions of orbital origin.

4. Hypertrophied inferior turbinate. 


\section{OBSERVATION AND RESULTS}

The total number of patients examined in the year 2015 from January to December was 88,295. Among them 34,826 (39.44\%) patients attended with nasal symptoms; $111(0.31 \%$ in the study group with nasal symptoms) patients presented with mass lesions of the nose.

All the cases were treated surgically by one of the following surgical methods - Functional endoscopic sinus surgery, Intranasal endoscopic assisted excision, Lateral rhinotomy, Weber-Ferguson approach, Caldwell-Luc approach, combination of the above approaches or external excision.

The excised specimens were sent for histopathological examination and the reports were categorized according to the type of lesion.

\begin{tabular}{|c|c|c|}
\hline Sex & Incidence & Percentage \\
\hline Males & 68 & $61.26 \%$ \\
\hline Females & 43 & $38.74 \%$ \\
\hline \multicolumn{3}{|c|}{ Sex Distribution } \\
\hline
\end{tabular}

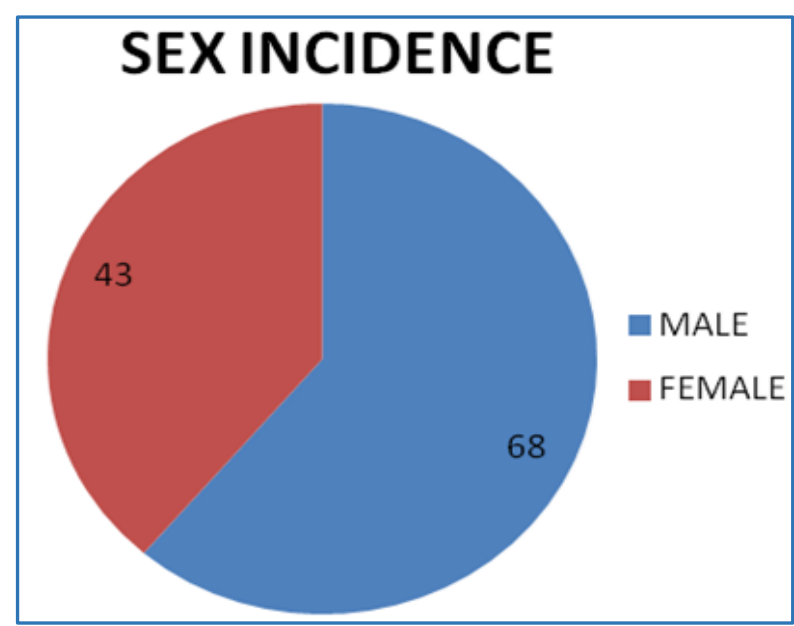

Among the study group which consisted of 111 patients, it was observed male predominance that is $68(61.26 \%)$ were males and 43 (38.74\%) were females.

\begin{tabular}{|c|c|}
\hline Age Group in Years & Incidence \\
\hline $0-20$ & 16 \\
\hline $21-40$ & 50 \\
\hline $41-60$ & 32 \\
\hline$>60$ & 13 \\
\hline \multicolumn{2}{|c|}{ Age Distribution } \\
\hline
\end{tabular}

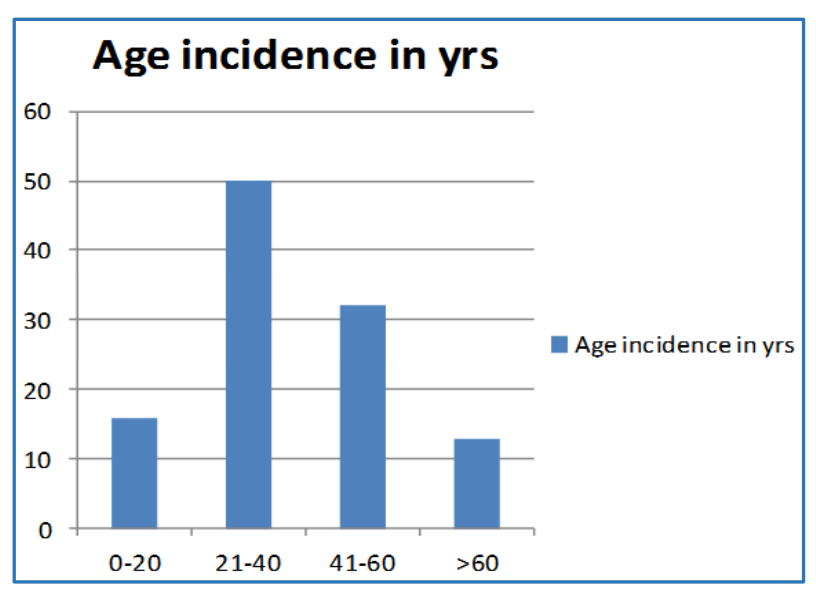

In this series, it was observed that most of the patients treated belonged to the age group of $21-40$ years ( $45.04 \%$ out of all patients with mass lesions of nose), while the next common age group effected is $41-60$ years $(28.8 \%)$.

Out of all patients with mass lesions of the nose, 81 patients had Nasal polyposis which accounts for $73 \%$ while 32 patients had lesions other than Nasal polyposis accounting for $27 \%$ of the mass lesions. Among the benign tumours and lesions of nose other than polyps, Nasopharyngeal angiofibroma and inverted papilloma were more in number (18.75\% each), while tumours such as fibrous dysplasia (9.3\%), bleeding polyposis septum - 4 (12.5\%) Angiomyxomatous polyp - 1 (3.12\%), salivary fibrous tumours - 2 (6.25\%), pleomorphic adenoma - 1 (3.12\%), adenomatoid odontogenic tumour $(3.12 \%)$ were rare. Some of the mass lesions occurred due to infective pathology are Rhinosporidiosis (12.5\%), 4 while some lesions were due to inflammation followed by degeneration of the polyps (6.25\%), maxillary mucocele was seen in 1 patient (3.12\%). ${ }^{5}$ Nasopharyngeal angiofibroma and Inverted papilloma were commonly observed benign tumours. As most of the common lesion found in the nasal cavity and paranasal sinuses is polyp, most of the results of polypoidal lesions were compared with other studies.

\section{Type of nasal masses}
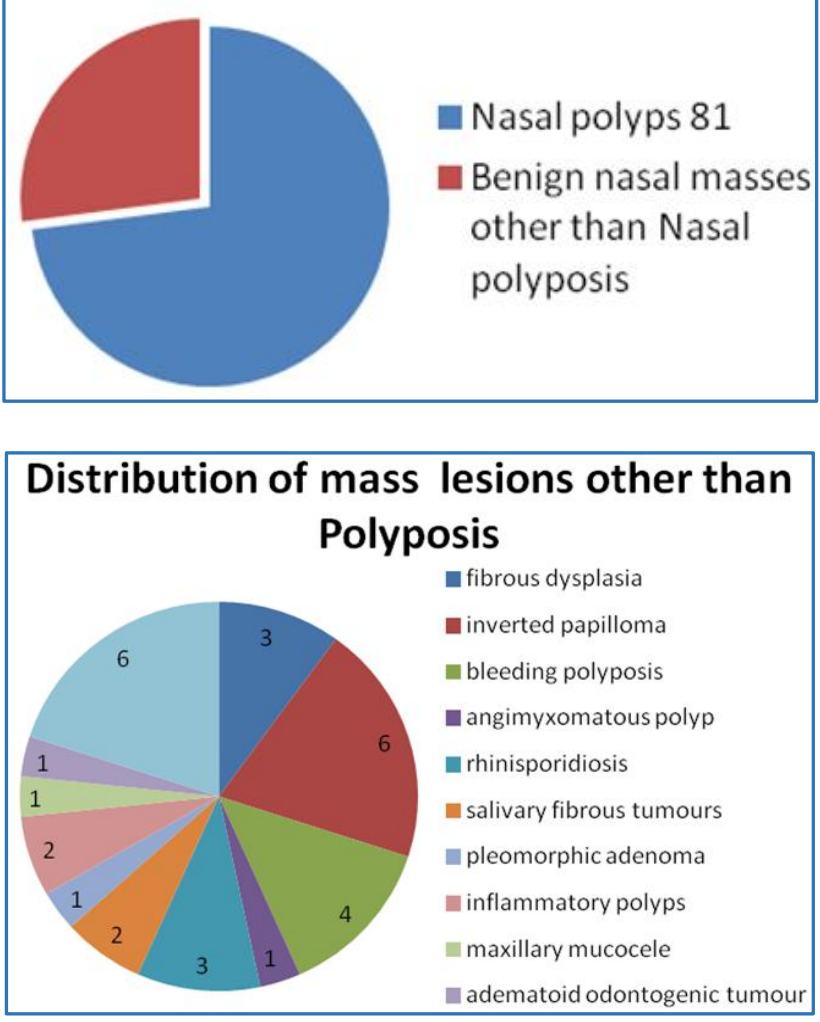

\section{DISCUSSION}

Among the study group of mass lesions of the nose, i.e. 111 patients, $73 \%$ of patients with Nasal polyposis due to allergy were identified. ${ }^{6}$ This shows the significance of anti-allergy treatment with anti-histaminics and local corticosteroid sprays with avoidance of exposure to allergic food, dusty environment, polluted gases, fragrant fumes, domestic pets and occupational allergens. ${ }^{7}$ 
Remaining patients had lesions of the nose other than nasal polyposis, common among them being tumours like Juvenile Nasopharyngeal Angiofibroma constituting to 18.75\%. Juvenile Nasopharyngeal Angiofibroma was observed to be more common in adolescent males and it accounts for $0.05 \%$ of all head and neck tumours with an incidence of 1:5000 to $1-60,000$.

According to Shafik N. Wassef et al, Inverted papilloma is relatively uncommon neoplasm of nasal cavity constituting $0.5 \%$ to $4 \%$ of all primary nasal tumours with an incidence of $0.6-1.5$ cases per $1,00,000$ per year. $^{8}$ In this study, there were 6 cases of Inverted papilloma noted which constituted $18.75 \%$ of all lesions in the nose other than Nasal polyposis.

Other tumours like Fibrous dysplasia, Rhinosporidiosis, Salivary gland tumours, Pleomorphic adenoma, Angiomyxomatous polyp and Maxillary mucocoele are rarely encountered.

\section{CONCLUSION}

Polyp is the most common lesion of nasal cavity and paranasal sinuses in different age groups, while Nasopharyngeal angiofibroma in 15-25 years' age group and Inverted papilloma in $5^{\text {th }}$ and $6^{\text {th }}$ decades were most common benign tumours with predominance in males.

Early Nasal polyposis can be treated primarily with medical line of management. The cases refractory to medical measures are considered for surgical treatment. Sinonasal polyposis are often associated with nasal allergy. Hence, Allergen avoidance is an essential step in managing them. This shows the need of awareness regarding allergy and regular prolonged usage of required medication like intranasal corticosteroid sprays and oral anti-histaminics for the treatment of allergic rhinitis. Avoidance of unhealthy cultural practices and usage of ponds for taking bath, washing clothes can prevent occurrence and spread of Rhinosporidiosis infection. As the Nasal polyposis is the commonest cause of nasal obstruction in mass lesions of nose, still more studies should be conducted with a focus on origin of polypi and nasal allergy. ${ }^{9}$

\section{REFERENCES}

1. Zafar U, Khan N, Afroz N, et al. Clinicopathological study of non-neoplastic lesions of nasal cavity and paranasal sinuses. Indian J Pathol Microbiol 2008;51(1):26-9.

2. Hassan al-H, Hattar N. Clinicopathological study of sinonasal lesions at King Hussain Medical Center. JRMS 2002;9(2):16-8.

3. Aukema AA, Mulder PG, Fokkens WJ. Treatment of nasal polyposis and chronic rhinosinusitis with fluticasone propionate nasal drops reduces the need for sinus surgery. J Allergy Clin Immunol 2005;115(5):1017-23.

4. Arseculeratne SN. Recent advances in rhinosporidiosis and rhinosporidium seeberi. Indian J Med Microbiol 2002;20(3):119-31.

5. Oronez NG, Rosai J. Respiratory tract. In: Rosai and Ackerman's surgical pathology. 9th edn. vol. 1. St Louis, MO: Mosby 2004:308-24.

6. Messerklinger W. Role of the lateral nasal wall in the pathogenesis, diagnosis and therapy of recurrent and chronic rhinosinusitis. Laryngol Rhinol Otol 1987;66(6):293-9.

7. Mygind N. Advances in medical treatment of nasal polyps. Allergy 1999;54(Suppl 53):12-6.

8. Wassef SN, Batra PS, Barnett S. Skull base inverted papilloma: a comprehensive review. ISRN Surg Article ID 175903, 2012;2012:p 34.

9. Bateman ND, Fahy C, Woolford TJ. Nasal polyps: still more questions than answers. J Laryngol Otol 2003;117(1):1-9. 